\title{
Operation of transport companies in terms of the sustainable growth of the region
}

\author{
Roman Averbukh ${ }^{1,}{ }^{*}$, Galina Kononova ${ }^{1}$ and Vsevolod Tsiganov $^{2}$ \\ ${ }^{1}$ State Institute of Economics, Finance, Law, and Technology, Roschinskaya, 5, Gatchina, 188300, \\ Russia \\ ${ }^{2}$ JSC "ElektroRadioAutomatica" per. Grivtcova 1/64, Saint-Petersburg, 19000, Russia
}

\begin{abstract}
The article highlights the influence of the regional economic entities on the sustainable growth of the region. The nature of effect of the local conditions on the efficiency of the entrepreneurial activity is determined. The definition of sustainable growth of the region is clarified. Transport organizations are taken as a study subject. The main operational results of transport organizations, that are directly related to the living standards, are identified and classified. The extended algorithm for the correspondence between organizations' efficiency and growth of the region is developed. Priority factors, that aim to increase the performance of transport companies, are determined. These factors include active use of digital technologies in carriage of passengers and cargo traffic as well as application of principles of behavioral economics in human resource management. Issues of behavioral economics are considered from the standpoint of the problem of growth in labor productivity.
\end{abstract}

\section{Introduction}

Current high level of uncertainty in the economic and social field, non-linear territory development and numerous and diverse character of the elements, which function within the region and interact with the external environment, do not only define the urgency of the problem to ensure the sustainable development of region, but also mark it as the central problem in the management of the region.

There are quite a number of definitions of the concept of sustainable development of the region, that are couched in scientific articles and in some legislative acts. The definitions, which dwell on the environment preservation and town-planning requirements, are the most popular. Considering them from the general point of view, the sustainable growth of the region can be presented as a supervised long-term process of development of the social and economic potential of the territory, that is carried out to ensure the positive progress in people's lives. Whereas the following mandatory conditions, such as organizational structure of the region and economic optimization within its subsystems, must be executed.

This definition does not contradict the approach taken by the United Nations members in setting the goals of sustainable development. The key indicators for this were indicators of sustainable development as economic growth, social integration and environment

\footnotetext{
${ }^{*}$ Corresponding author: mail@gief.ru
} 
preservation [1], which were taken into account when choosing the main features for the grouping of those activity results of the transport company that are of interest in the aspect of sustainable growth of the region.

In support of the study relevance, it can be noted that the objectives to improve the regional transport system take one of the central places in documents, which reflect the development prospects of the region. The services of transport companies are used in all spheres of economic activity, and also meet the needs of the population in business, home and cultural trips. Therefore, there is no doubt that, to a large extent, the efficiency of the process of growth of the social and economic potential of the territory is ensured by the increase in the efficiency of the operation of regional economic entities, including transport organizations.

\section{Study purposes}

Thus, the significance of the impact of transport organizations on the sustainable development of the region is beyond doubt. Therefore, it is important, firstly, to choose the right assessing technologies and key performance indicators of transport companies operation and, secondly, to clarify the goal-setting of the companies' management at the developing stage, as well as in the process of further monitoring over the plan implementation. To do this, it is necessary to identify the nature and orientation of the activity impact of transport organizations on the sustainable growth of the region and, on this basis, to determine the most relevant factors to improve the performance of this activity, which has become the goal of the research. Some of those are presented below.

\section{Problem structuring and study results}

In the course of the study of the nature and direction of the impact of the operations of transport organizations on the region, the following provisions were developed and taken into account that made it possible to structure the problem under study:

-the anticipated level of sustainable growth of the region is achieved through the preservation and improvement of the mandatory properties of the socio-economic system. Regarding the transport company activities, their role in the development of such a property as the integration of the region (built-in and with the subjects of the external environment) should be primarily discussed. The economic value in developing this property is when the integration processes are frustrated, the optimality of economic relations and proportions is broken down, which prevails in competitive regions. Therefore, economic stability of the region is exposed.

Any disintegration can cause a decline in the stability of the region as a socio-economic system, which, as noted in [2], is of particular importance in the era of economic change.

Therefore, the operation of transport organizations is proposed to be considered as an instrument of integration, which depends, to a certain extent, on both the socio-economic integrity of the region and on the reliability of its numerous and multidirectional interactions with the external environment.

-in this case, the operation results of transport companies are deemed estimating if those are directly related to the economic health of the region, safe and comfortable living, that mutually improve the living standards of the population;

-there is no need to analyze the magnitude and dynamics of the entire set of performance indicators when regional authorities and public organizations monitor the performance of transport companies. The impact of the activity results of transport companies, firstly, differs by the effect on the stability level of the region and, secondly, 
depending on the nature of the results, it is associated with the emergence or solution of extremely different problems of the region. The selection of the analyzed indicators should be justified from the viewpoint of the relevance of the problems and with account of the transparency degree of transport organizations. The range of indicators should be appropriate for use by various regional government bodies and public organizations: for instance, associations for the consumer right protection, environment preservation in the region, social care of certain population groups, etc.

The extended algorithm for the impact of the operation performance of transport companies on the sustainable growth of the region is shown in the figure.

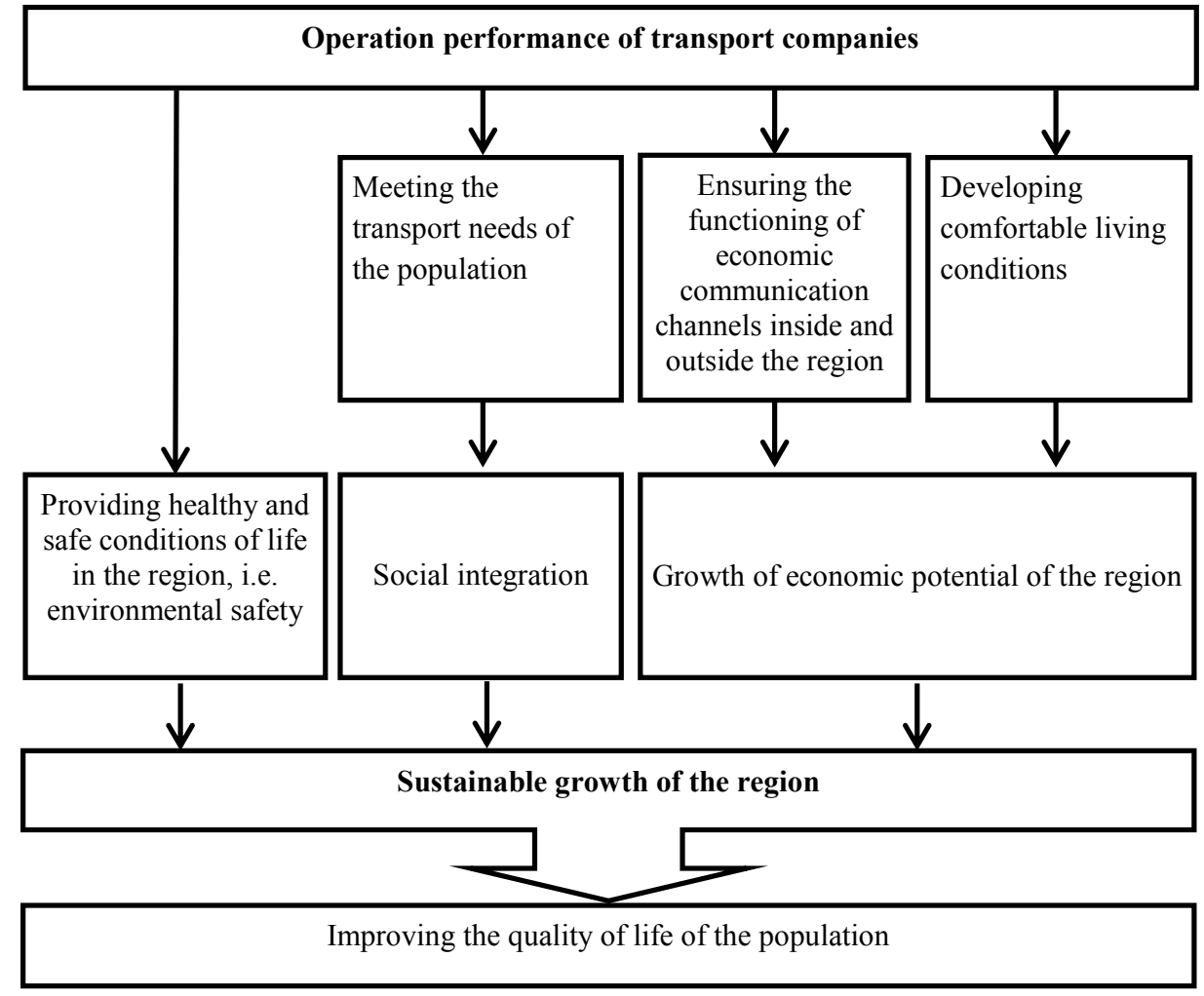

Fig. 1. Impact of the transport company performance on the sustainable growth of the region.

The following grouping of the results of the transport company activity was adopted for the algorithm. It is based on indicators of the sustainable growth of the region.

1.The activity results of transport organizations, that ensure life safety in the region, include the reduction of environment pollution (which regards road transport), the reduction in the number of road accidents compared to the population of the region, the increased reliability of transport services in a case of emergency (emergency medical care, natural disasters, accidents associated with utility services, etc.).

2.Results, that are connected with the constantly growing and qualitatively changing transport needs of the population, meeting which to a certain extent tackles the problem of social integration. This group can include increase in the degree of regularity of public transport, reduction of the waiting interval when making business, work and cultural trips, increase of the average travel speed, improvement of the service quality of suburban, intercity and international passenger transport.

3.Results, achievement of which ensures the growth of the region's economic potential, include timeliness and speed of delivery of goods to enterprises of other industries (both 
inside and outside of the region), safety of cargo, ensuring the stable functioning of transport corridors, and improving the reliability of regional logistics. Achievement of competitive level of regional transport organizations in interregional and international transportation is also economically valuable. The results of this group are a prerequisite for eliminating threats and dangers, which are associated with the probability of disrupting economic communication channels both within the region and with the subjects of its external environment.

4.Operation results of transport companies that contribute to the formation of a comfortable living conditions in the region is the part of the environment, which is created by humans. That is technosphere. The following results can be named here: timeliness of household and industrial garbage disposal, quality of cleaning of residential areas, the adaptability of passenger transport to service people with disabilities, etc.

The comfortable living conditions, firstly, is a factor to maintain the health and labor efficiency of the population. Secondly, it increases the attractiveness of the region as a place of residence, and therefore contributes to the inflow of labor resources. Thus, the results of this group respectively ensure the growth of the region's economic potential [3].

Let us now turn to the problem of increasing the efficiency of transport organizations, which is formed under the influence of numerous factors, both external and internal.

The enumeration of external factors can be begun with a mention of the climatic and geographical conditions, that influence vehicle operation, and be continued with a rather large list of factors that arise due to changes in the overall social and economic situation in the country and the situation prevailing in international markets of transport services. The general list includes factors that are formed at the regional level. Among the latter one should mention such factors that have a significant impact on the performance of transport companies, such as condition of roads, situation in the local labor market, system of regional support for small and medium-sized businesses, the policy of the region towards the development of vocational education, etc.

The list of in-house performance factors is also quite large, and their impact on the results of the organization's activities is very appreciable. However, in connection with the inevitable need for constant monitoring of the rapidly changing and often aggressive external environment, transport managers direct their main efforts to adaptive measures and do not pay due attention to the in-house factors [4].

At the same time, information about the weight and nature of the influence of in-house factors largely tackles the problem of choosing the most effective methods for increasing the transport company performance. The studies, that were conducted in transport organizations, give grounds to assert that such methods include the introduction and rational use of digital technologies, as well as active adherence to the principles of the behavioral economy.

\section{Discussion}

So, for instance, the use of digital technologies in the transport companies provides a wide range of opportunities to improve their performance rate. It allows to ensure timeliness of cargo delivery, excludes unplanned waiting for the passengers, determines the reliability of the logistical chain, where transport companies are its elements, and also leads to a significant increase in the mileage efficiency of the rolling stock. Positive dynamics of this coefficient not only improves the financial performance of the transport organization, but also reduces the level of environmental pressure.

As for the behavioral economy, here, in the light of the problem being scrutinized, it is worth noting that the behavior of employees determines the results of the organization's activities, and, therefore, the interactions of workers with the transport company can be 
described by a set of actions that meet or conflict with the economic interests of the organization.

From this perspective, it is possible to highlight the key tasks of personnel management, among which a special place is occupied by the tasks to improve the professional reliability of personnel [5].

The professional reliability of personnel in conditions of active introduction of innovative technologies largely depends on the knowledge management system. Therefore, the raise of awareness towards improvement of the professional training of workers is justified.

This is particularly associated with the emergence of a sufficiently large number of scientific publications that deal with general issues of the formation of intellectual capital in enterprises that actively introduce innovations and methods for effective interaction between entrepreneurs and universities [6]. The foreign experience is of interest. Some publications highlight the promotion of career preparation and production internships within the dual education system with active support of local authorities.

Rational use of methods of behavioral economy positively affects the level of labor productivity, which is important, since the dynamics of this indicator in the transport industry for a fairly long time cannot be called comforting.

The problem of productivity growth is relevant not only for the transport sector. According to the data of the Analytical Center affiliated to the Government of the Russian Federation, a steady growth in labor productivity has not been registered yet in the overwhelming majority of the regions of the country [7].

Thus, some researchers suggest to use the indicator of labor productivity as an indicator of the achievement of the goals of sustainable development of territories [8].

With this in mind, it should be noted that the growth of labor productivity in transport industry has not only the in-house effect, but also the external one. The effect consists in the possibility to use the released labor resources in regional organizations that carry out other types of activity, and, thus, it acts as a factor in increasing of the region's economic potential. This circumstance should be taken into account when the support and encouraging of the efforts of transport organizations are aimed at increasing labor productivity.

However, despite the economic value of measures aimed at improving labor productivity, the labor productivity growth index is not included in the mandatory indicators, that are used to assess the efficiency of the regional economic governance bodies. As a result, the region's authorities currently do not have the necessary information on the state of the problem and, therefore, are not asked to stimulate higher labor productivity in regional organizations.

\section{Conclusion}

On the basis of the study the following conclusions have been drawn.

1. The choice of the leading factors of sustainable growth of the region, the influence of which should be taken into account in the process of forecasting and monitoring in the field of solving the problems of regional transport systems, is to improve the living standards of the population. In accordance with this criterion, the leading factors of sustainable growth of the region, related to the performance of transport organizations, are:

- Growth of the region's economic potential, ensuring its competitiveness and investment attractiveness;

-social integration, development of which depends on the degree of transport accessibility, both for the local population, and for the flows of people entering and leaving the region; 
- preservation of optimal parameters of the environment of the region by reducing the transport environmental pressure;

- prevention of emergency situations due to the transport, and timely elimination of their consequences;

-formation of a comfortable living conditions in the region in terms of the technosphere.

2. Since the region is an open socio-economic system, it can be argued that the impact of the transport company efficiency on the sustainable development of the region is transformed through a state of such a systemic quality as integration. This influence determines the degree of socio-economic integrity, the level of reliability of its economic interactions with the subjects of the external environment.

3. The performance of transport organizations, playing a party in the sustainable growth of the region, is in turn influenced by regional factors, which makes it necessary for the regional government to actively participate in creating conditions for the effective operation of not only carriers but also other links in the region's logistical systems.

4. Priority factors for improving the performance of transport organizations are the rational use of digital technologies in the operational management of the goods shipment and passenger carriage, as well as the implementation of the principles of the behavioral economy in the process of personnel management in order to increase labor productivity.

5. The research results can be applied in the design of a strategy for the development of the transport system in the region, in the process of monitoring over the strategy implementation, as well as in selecting incentives to increase the effectiveness of entrepreneurial activities within the transport sector.

\section{References}

1. R.N. Averbuh, V.R. Kovalev, G.I. Lukin, ZHurnal pravovyh i ehkonomicheskih issledovanij 1, 7-12 (2018)

2. A. Larionov, Yu. Larionova, MATEC Web of Conferences 106, 08032 (2017)

3. A. Larionov, MATEC Web of Conferences 106, 09022 (2017)

4. A. Larionov, MATEC Web of Conferences 170, 01103 (2018)

5. I. Adizes, M. Cudanov, D. Rodic, Amfiteatru Economic 19(44), 232-248 (2017)

6. J. Bruneel, P. D Este, A. Salter, Research Policy 39, 858-868 (2010)

7. N. Hoffman, R. Schwartz, Gold Standard: the Swiss Vocational Education and Training System, International Comparative Study of Vocational Education Systems (National Center on Education and the Economy, Washington, 2015)

8. R.B. Schwartz, Journal of Social Issues 72(4), 740-759 (2016)

9. Transforming our world: the 2030 Agenda for Sustainable Development (United Nations General Assembly. Distr., 2015) 